\title{
Enhancing Manufacturing Process Education via Computer Simulation and Visualization
}

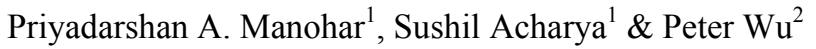 \\ ${ }^{1}$ Engineering Department, Robert Morris University, Moon Township, PA, USA \\ ${ }^{2}$ School of Communications and Information Systems, Robert Morris University, Moon Township, PA, USA \\ Correspondence: Priyadarshan A. Manohar, School of Engineering, Mathematics and Science (SEMS), Robert \\ Morris University, John Jay 119B, 6001 University Boulevard, Moon Township, PA 15108-1189, USA. Tel: \\ 1-412-397-4027. E-mail: manohar@rmu.edu
}

Received: June 30, 2014

doi:10.5539/jel.v3n3p172
Accepted: July 28, $2014 \quad$ Online Published: August 24, 2014

URL: http://dx.doi.org/10.5539/jel.v3n3p172

\begin{abstract}
Industrially significant metal manufacturing processes such as melting, casting, rolling, forging, machining, and forming are multi-stage, complex processes that are labor, time, and capital intensive. Academic research develops mathematical modeling of these processes that provide a theoretical framework for understanding the process variables and their effects on productivity and quality. However it is usually difficult to provide the students with hands-on experience of experimentation with process parameters which leads to disconnect between engineering education and industrial needs. In order to solve this problem, interdisciplinary student projects were undertaken at author's institution to develop computer simulation tools that would facilitate process visualization, experimentation, exploration, design and optimization. The hypothesis is that these new computer-based tools would enhance educational experience for the manufacturing engineering students as assessed by the ABET-derived educational outcomes and also based on Bloom's cognitive outcomes modified for STEM disciplines.

The first system described in this paper is the visualization of metal ingot production schedule in an industrial setting that provides a basis for interactive decisions. The graphical user interface is created to visualize the schedule according to the specific characteristics of the machines. Another example of process simulation presented in this paper is the design and analysis of flexible rolling technology in industrial processing of low carbon steels. Process simulation tools designed in both cases allow new process sequences to be generated by breaking down existing process routes into key elements and then by recombining them to generate novel alternative and more efficient hot processing sequences. This enables the identification of an optimal process sequence for specified steel compositions that also satisfies simultaneous design criteria such as process feasibility and property maximization. It is proposed that incorporation of such computer simulation tools in the pedagogy would be highly effective to enhancing and enriching undergraduate manufacturing education.
\end{abstract}

Keywords: process simulation, optimization, mathematical modeling

\section{Introduction}

Manufacturing and mechanical engineering curricula typically include one or more courses where the students are introduced to industrially significant, primary manufacturing process such as casting, rolling, forging, forming, and welding. Such processes are best taught in a hands-on manner using lab scale equipment or via industrial visits. While such lab activities are important for student's understanding of the subject matter they are both expensive and cumbersome. In order that the students achieve the most benefits from hands-on lab exercises, they must therefore be well prepared prior to conducting the hands-on activities. In this regards, this paper proposes that the computer simulation tools offer a wonderful opportunity to enhance the teaching-learning process. The paper describes a couple of process simulation and visualization tools developed by the students at the authors' institution as part of their project work.

It is important to understand how the steel properties change during processing for designing appropriate process control, conduct process optimization as well as to predict the properties at room temperature of the final product. To achieve these objectives, traditional tools involve experiments done with laboratory scale hot rolling mill or 
by conducting trials on pilot plants. However, such experimentation is both expensive and time consuming and so the academic setting has mostly relied on the mathematical modelling of the phenomena to educate students about the processing. The mathematical models abstract the processes using several simplifying assumptions and the metallurgical phenomena, material behaviour and the reaction rate kinetics gets hidden behind these models and assumptions. The entire process then becomes a big black box. The students are unable to see what can be changed and what must remain constant and thus analytical models do not provide a comprehensive picture of the process behaviour. In the proposed simulation tools, the number of assumptions made is kept to a minimum and the assumptions are explicitly stated. The process becomes transparent where the student is able to sample data from all the steps of the process sequence which enhances student's understanding of the processing. The proposed computation tools thus allow the students to gain deeper insight into complex industrial processing by conducting computer-based process simulations.

The complex task of process visualization of both casting and downstream rolling using computer programming and modeling was undertaken as interdisciplinary student projects. The work was supervised by manufacturing and software faculty and implemented in Visual $\mathrm{C}++$. The paper will demonstrate this approach where the students developed process visualization tools as part of their manufacturing engineering curriculum. The proposed method solves the problem of giving students an opportunity to experiment with a large-scale industrial manufacturing process using computer simulation and visualization which they would otherwise not have had. The educational innovation in the proposed work is thus about solving a critical pedagogical problem of teaching large-scale industrial manufacturing processes to a relatively large number of students, without the need for expensive laboratory set ups in academic settings. This is done by developing teaching tools that simulate extremely complex manufacturing process sequence deployed in industry. These tools are currently lacking and there is no real way for the students to gain an understanding of how the process works, which parameters can be tweaked to optimize the process, and how to predict material properties of the products made by these manufacturing processes. So the paper describes two such new process simulation and experimentation tools to enhance the teaching and learning process.

Over the past three decades a number of computer based expert systems have been developed around the world for a more efficient solution of manufacturing problems in several areas such as diagnostic, design, planning, scheduling, process control, and quality control within the iron and steel industry (Bloom, 1956; Girgis, 2010). More recent research focus has been on the application of Artificial Intelligence (AI) to the hot rolling of the steel (Goldratt \& Fox, 1984; Greene, 1996). The primary objective of steel rolling to obtain the desired shape has been augmented by the need to produce steel products with a range of desired properties such as strength, toughness, weldability, and formability at low overall cost. Going further upstream in primary processing industry, the optimization of metal ingot casting schedules presents significant challenges as market needs change rapidly. In this case, production planning decisions must be made quickly to be responsive to the market. Quite often judgments need to be made when objectives and constraints are not even readily quantifiable. In order to avoid knee-jerk response to the merging situation, it is important that response is evaluated using appropriate tools such as an information system. The information system should then be able to visually present production plan with its capacity and load, allowing human interaction to make changes while showing the ramifications by immediate feedback (Manohar, 2008, 2010; Manohar, Lim, Rollett, \& Lee, 2003). The human planner would thus be able to promise a delivery based on the available production capacity without causing problems in other areas of production scheduling.

\section{Ingot Casting System}

Production planning is known to be an extremely difficult task due to rapidly changing market needs, a high degree of complex logistics involved, and therefore the use of the right tool will make the job easier and may result in higher efficiency and higher profits (Manohar, Shivathaya, \& Ferry, 1999). The production planning problem of metal ingots casting is addressed in the system presented in the present work. The solution strategy is based on an analysis of the bottle neck of the assembly line (Mcllvaine, 1996), where the melting furnace and the heating oven have been identified as the production machines casing bottleneck. The system approach is based on visualizing the production capacity and load on the schedule of these machines. An interactive load graph is designed to visualize the effect of production capacity and load on the production scheduling of these machines. Using the interactive load graph the planner can then interact with the production schedule and make changes manually, while relevant information about the impact of the changes may be shown immediately through visual feedback. 
The user interface design is the most important aspect of system visualization. In metal ingot casting, the bill of materials is relatively simple: the bill of materials for each alloy specifies the ingredients proportion to be mixed with the metal ore. The manufacturing process is shown schematically in Figure 1. The metal ore mixture is first poured into the melting furnace. In the next step the molten mixture is released into the dropping tool where it is casted into alloy ingots. The ingots then need to go through the pre-heat oven for heat treatment. Each type of ingot product will have its own recipe that details the necessary temperature profile to be used in the heat treatment process. This recipe is important for the preferred metallurgical properties of the ingot.

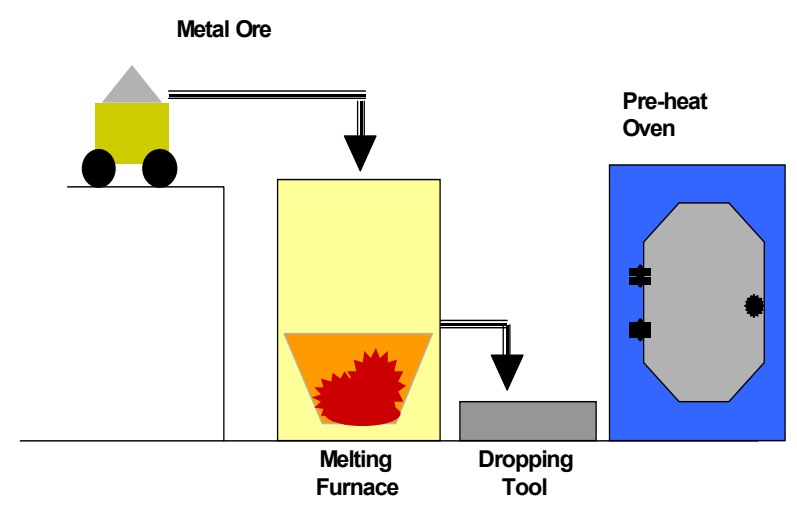

Figure 1. The metal ingot casting process

Figure 2 depicts the design of a typical production plan with the time bucket size of one week. If the machine is available to operate 24 hours a day, 7 days a week then the maximum feasible load is calculated to be $7 * 24=$ 168 hours. In this diagram each colored block represents a job assigned for production within that week. The height of the blocks represents the load on production capacity which is defined as the time duration the machine will be occupied by the job. Using the production plan the planner can observe production capacity availability and overloading. Production jobs assigned to a particular week can have three statuses: early for production, late for delivery, or optimal. To represent this information the blocks are color-coded with early jobs in blue, late jobs in red, and optimal in green. The planner can interact with the load graph by dragging and dropping a block. The system permits the planner to move blocks from one week to another, re-arrange the order of the blocks within each week, or split up a block and move the individual blocks. The ramifications of changes made are automatically computed and provided as a visual feedback to the planner. At this point the planner can decide on keeping the change if it is feasible or continue rearranging the jobs.

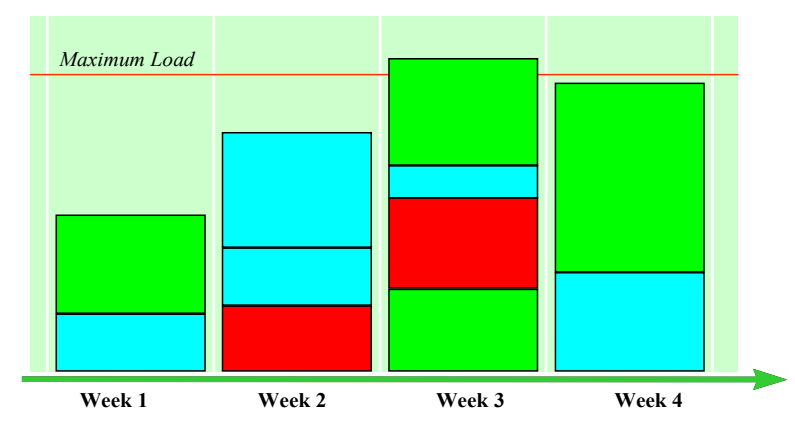

Figure 2. Production schedule showing capacity and load

In addition the planner can use each of these blocks to drill down to see detailed information about the order. The system is capable of displaying information like product code, customer order number, and customer name. The planner is also able to display any of this information as label on the block. Further details of the system are given in a paper by (Noderer \& Henein, 1996). 


\section{Hot Rolling System}

The overall industrial process for manufacturing steel products is shown schematically in Figure 3 while wire rod rolling process studies in this work is shown schematically in Figure 4. Figure 3 gives a global perspective of steel processing where important process steps are shown in sequence: starting from impure liquid carbon steel, steel purification in converter, then continuously casting into steel billets that are 50-80 mm thick or the steel can be cast into $200-250 \mathrm{~mm}$ thick ingots, the billets or ingots are reheated to prepare them for further hot rolling into bars, subsequent to hot rolling the bars are cooled, coiled, packaged and shipped.

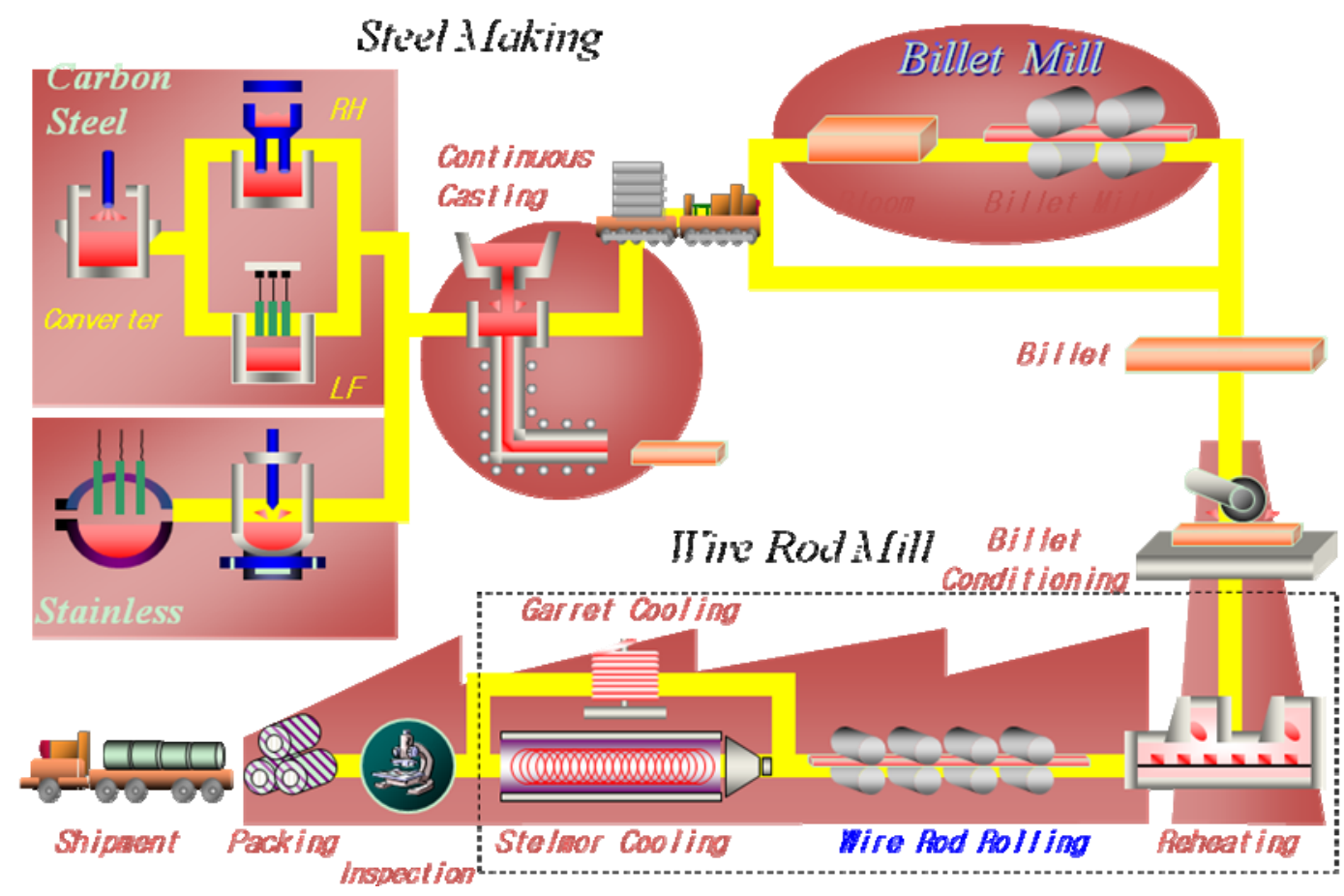

Figure 3. Overall process sequence to manufacture steel products

The details of the process sequence in the box above marked "Wire Rod Rolling" are shown in Figure 4.

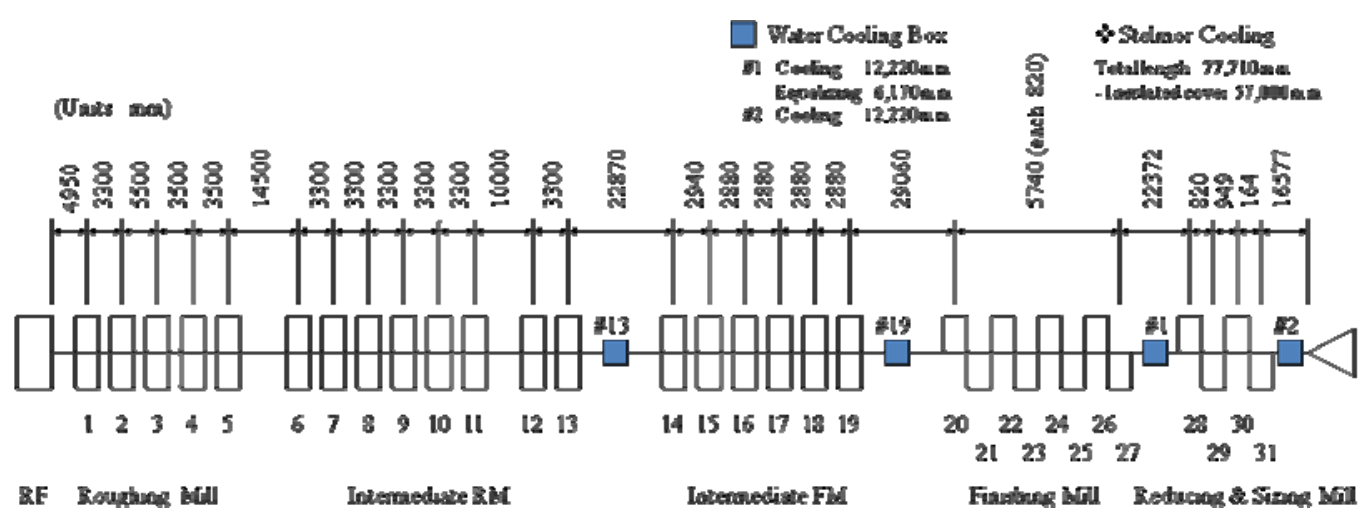

Figure 4. The details of the multi-stage wire rod rolling process selected for visualization

The details of the process shown in dotted box in Figure 3 are shown schematically in Figure 4. Figure 4 shows how a $250 \mathrm{~mm}$ thick slab gets rolled down to $5 \mathrm{~mm}$ thick steel plate in a sequence of 31 hot rolling passes with 
several cooling stations during the continuous processing. It is therefore important to understand how the steel properties change during processing for designing appropriate process control, conduct process optimization as well as to predict the properties at room temperature of the final product. To achieve these objectives, traditional tools involve experiments done with laboratory scale hot rolling mill or by conducting trials on pilot plants. However, such experimentation is both expensive and time consuming and so the academic setting has mostly relied on the mathematical modelling of the phenomena to educate students about the processing. The mathematical models abstract the processes using several simplifying assumptions and the metallurgical phenomena, material behaviour and the reaction rate kinetics gets hidden behind these models and assumptions. The entire process then becomes a big black box. The students are unable to see what can be changed and what must remain constant and thus analytical models do not provide a comprehensive picture of the process behaviour. In the proposed simulation tools, the number of assumptions made is kept to a minimum and the assumptions are explicitly stated. The process becomes transparent where the student is able to sample data from all the steps of the process sequence which enhances student's understanding of the processing. The proposed computation tools thus allow the students to gain deeper insight into complex industrial processing by conducting computer-based process simulations.

The process was initially mathematically modeled and implemented within an expert system (Shivathaya, 1997; Takahashi, 2008). The results of the calculations made by expert system were then collated and used as input for visual display. The program was implemented in $\mathrm{C}++$ and a user interface was developed as shown in Figure 5. Figure 5 shows the input interface for the user he can give details of the steel composition (grade) being processed, the initial and final thickness of the slab being rolled, process sequence including how many processing steps are needed and finally the cooling rate subsequent to mechanical processing of the steel product. In the drop down menu for the last items one can choose slow cooling like air cooling at $1{ }^{\circ} \mathrm{C} / \mathrm{s}$ to rapid cooling such as water jet cooing where the cooling rate can be as high as $150^{\circ} \mathrm{C} / \mathrm{s}$.

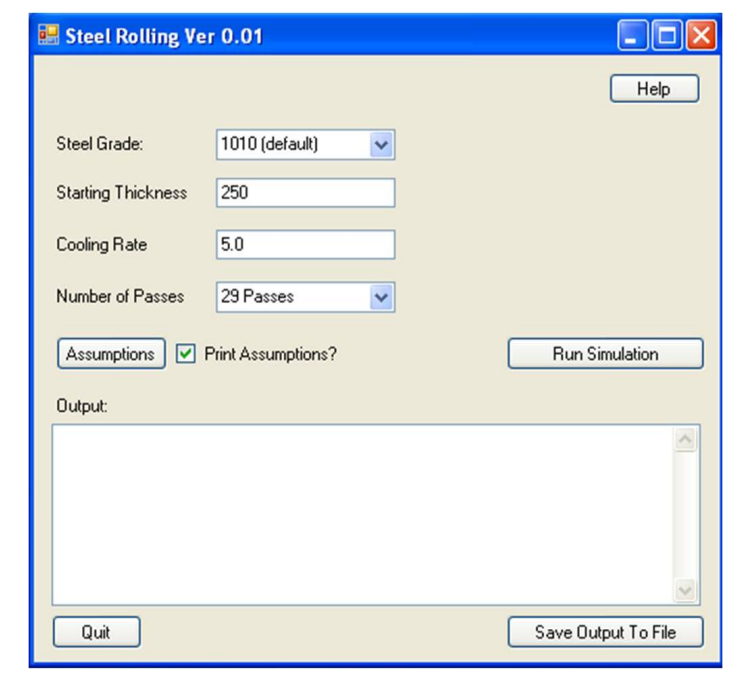

Figure 5. Example of a user interface developed for process simulation

A sample output of the program for medium C-Mn steel is shown in Figure 6 for a full-scale industrial rod rolling process (Shivathaya, 1997; Takahashi, 2008). The figure shows the evolution of austenite grain size as a function of process step. It can be seen from Figure 2 that the austenite grain size gets refined from an initial value of $\sim 300 \mu \mathrm{m}$ down to $\sim 3.3 \mu \mathrm{m}$ after finish rolling. The austenite grains coarsen to a size of $\sim 15 \mu \mathrm{m}$ during cooling from finish rolling temperature to the cooling stop temperature (CST). The predicted austenite grain size just before the onset of $\gamma \rightarrow \alpha$ transformation is $15.2 \mu \mathrm{m}$. The measured prior austenite grain size in industrially processed steel was determined to be $14.4 \mu \mathrm{m}$. The transformed ferrite grain size after industrial processing was measured to be $4.6 \mu \mathrm{m}$ while the predicted ferrite grain size is $4.9 \mu \mathrm{m}$. It is clear from this data that the predicted and experimentally measured mean austenite and ferrite grain size compare quite well, which validates the expert system for the computation of microstructural evolution in an industrial-scale rod rolling process. 


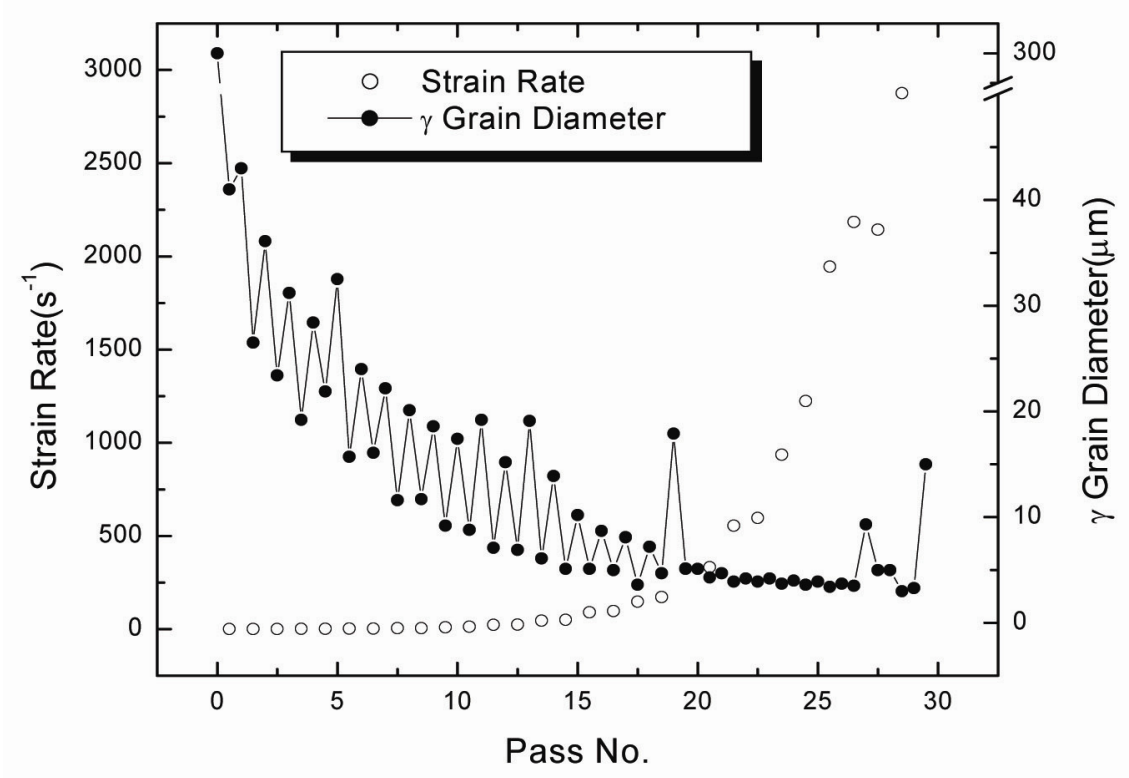

Figure 6. Predicted austenite grain evolution during rod rolling of a medium C-Mn steel

\section{Incorporation into Teaching}

The projects were implemented as student work as part of independent studies and subsequently used as educational tools in ENGR 3600 Production Engineering class. Some details of this course are provided in the sections below.

\subsection{Production Engineering Course Objectives}

Manufacturing is the engine that powers most industrial economies of the modern world. This course presents a balanced coverage of relevant scientific and technical fundamentals and real world practices in modern manufacturing. Purpose is to develop a sound understanding of technical nature of processes involved in producing most things we use in our day-today life.

The course incorporated a significant component of the hands-on lab exercises as listed below.

\subsection{List of Laboratory Exercises}

The following laboratory exercises and activities were conducted throughout the term:

- Metal riveting hammer - traditional workshop—sawing, milling, turning, facing, drilling, tapping, grinding, assembly, finishing

- Auto CAD/ SolidWorks - free-form design

- Rapid prototyping - fused deposition modeling

- Injection molding - demonstration and some operation of the machine- plastic rulers

- Powder metallurgy - aluminum and stainless steel powders - cold isostatic pressing

- Several manufacturing technology videos produced by SME, History channel

- Metrology — calipers, micrometers, go - no-go gages, tolerances

- 3D CMM - Co-ordinate Measuring Machine

In addition, sand molding and casting, MIG welding, sheet metal forming, vacuum forming for plastics and metal die casting labs have also been delivered when the schedule permitted it.

The rolling process simulation and visualization tool was made available to the students to experiment with and learn the effects of process variable on the properties of the products. The applicable ABT outcomes for the course are given in the following section. 


\subsection{Applicable ABET Criterion 3 Outcomes and Student Performance}

ABET outcomes 1, 3, 5, 7 and 8 and track-specific outcomes M2 and M4 are applicable for this course according to the existing course description.

Outcome 1: RMU Graduates have an ability to apply knowledge of mathematics, science, and engineering.

Outcome 3: RMU Graduates have and ability to design a system, component, or process to meet desired needs.

Outcome 5: RMU Graduates have an ability to identify, formulate, and solve engineering problems.

Outcome 7:RMU Graduates have an ability to communicate effectively

Outcome 8: RMU Graduates have the broad education necessary to understand the impact of engineering solutions in a global and societal context.

These particular ABET derived outcomes have been selected as the applicable outcomes for this class based on the body of knowledge taught in the course. The justification of the applicable outcomes is given as follows. Outcome 1 is generic to most engineering courses where students develop an ability to grasp and apply the fundamentals concepts of science, engineering mathematics to find solution to the given problem. Outcome 3 is about process design that meets customer needs and this is one of the harder outcomes to achieve. The course content includes process design and optimization through several methods such as analytical and mathematical modeling, lab-scale experimentation and the proposed computer-based simulation and experimentation. Outcome 5 related engineering problem solving is integral to most engineering classes. Outcome 7 is about effective communication, the so-called soft skill, is becoming increasingly important skill is today's globalized manufacturing supply chains. Finally, Outcome 8 is the broad education necessary to understand the impact of engineering solutions in a global and societal context where energy efficiency, water usage, carbon footprint and sustainability of the manufacturing processes are critical parameters that are subject to governmental restrictions in many countries. These concerns must be addressed in the education process along with the technical details of the processes taught so that the engineers gain a broad perspective on manufacturing engineering.

The student performance in each assessment task was regrouped in terms of ABET outcomes to work out the percentage of students that scored $\geq 80 \%$ marks for each of the specified ABET outcomes. The bar graph depicting this analysis is shown in Figure 7.

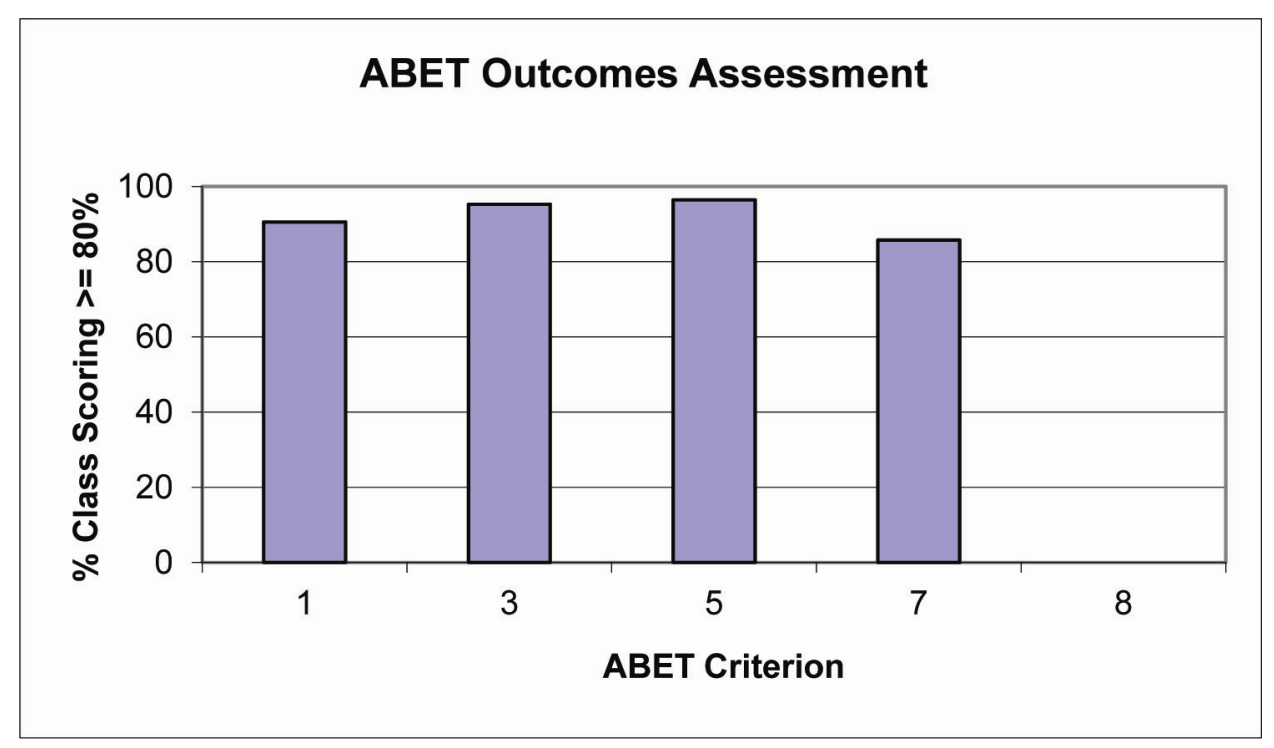

Figure 7. Class performance with respect to the applicable ABET outcomes

The current RMU-designated benchmark for class performance is $80 \%$

\section{Reflection:}

- It can be seen from Figure 7 that the class performance in this course is above the RMU-designated benchmark (at least $80 \%$ students in the class score $>=80 \%$ ) in applicable ABET outcomes $1,3,5$, and 7 . 
- ABET Outcome 8 was not assessed at this time.

\subsection{ABET Track-Specific Outcomes}

The following track-specific outcomes are identified for this course:

- M2: RMU Graduates have proficiency in process assembly, and product engineering and understand the design of products and the equipment, tooling and environment necessary for their manufacture.

- M4: RMU Graduates have an ability to design manufacturing systems through the analysis, synthesis and control of manufacturing operations using statistical or calculus based methods, simulation and information technology.

$85.7 \%$ students scored $>=80 \%$ points in Outcome M2 while $92.9 \%$ students scored $>=80 \%$ in Outcome M4, which is well above the RMU benchmark. Outcomes assessment for both of the applicable track-specific outcomes, M2 and M4, demonstrates that RMU benchmark is being met.

\section{Educational Enhancement}

The proposed methodology of incorporating computer based simulation tools in manufacturing engineering is expected to enhance educational experience and outcomes for the students. This aspect can be explained based on the Bloom's taxonomy for Science, technology, Engineering and Mathematics (STEM) disciplines and the development of critical thinking abilities and creativity in engineering students as explained below.

\subsection{Bloom's Taxonomy for STEM Disciplines}

The educational outcomes as a identified by Bloom (Wu, 1999) describes six levels within the cognitive domain: knowledge, comprehension, application, analysis, synthesis, and evaluation. A modified version of Bloom's taxonomy for Science, Technology, Engineering and Mathematics (STEM) disciplines has been recently proposed by Girgis (Wu, 2001). The proposed STEM taxonomy is presented in Figure 8 that the shape of a pyramid: the base represents the first level of engineering knowledge, and the levels increase in difficulty with each tier.

\begin{tabular}{l}
\hline $\begin{array}{l}\text { VII. Professional Engineering } \\
\text { Knowledge and Practices: life-long } \\
\text { learning experiences, skills and practices }\end{array}$ \\
VI. Project-based Knowledge: creative \\
conceptual, analytical, design, manufacturing \\
and management skills
\end{tabular}

V. Advanced Knowledge and Analytical Skills: inter-domain and open-ended problem solving skills

IV. Procedural Knowledge: working knowledge of solving multi-concept engineering problems

\section{Applied Conceptual Knowledge: solving simple} concept-based problems and conducting related laboratory experiments

II. Basic Conceptual Knowledge: learning, understanding, memorizing basic engineering concepts, definitions, terms, symbols, theories, laws and equations

I. Pre-knowledge Conceptual Experiences: hands-on laboratory experiences via demonstrations, physical models, practical applications to demonstrate, visualize and observe basic concepts

Figure 8. Conceptual and procedural knowledge and skills taxonomy 
As is seen from Figure 8, the taxonomy consists of seven units, or taxa, each representing one stage in acquiring the hierarchical engineering knowledge and skills structure. The first three taxa represent basic conceptual knowledge: experimental pre-knowledge and hands-on experiences, basic domain concepts, and first-level applied knowledge. The fourth taxon focuses on the procedural knowledge of solving multi-concept problems. The final three taxa represent the advanced level of solving inter-domain and open-ended problems, conducting design projects, and practicing professional engineering work. The relationship between cognitive domain educational objectives for the proposed taxonomy and Bloom's taxonomy is shown in Table 1, Bloom's educational objectives are mapped to the proposed STEM taxonomy.

Table 1. Comparison between Bloom's and the proposed taxonomy for STEM disciplines

\begin{tabular}{lllllll}
\hline $\begin{array}{l}\text { Bloom's } \\
\text { Taxonomy }\end{array}$ & Knowledge & Comprehension & Application & Analysis & Synthesis & Evaluation \\
\hline $\begin{array}{l}\text { Proposed } \\
\text { Taxonomy }\end{array}$ & I \& II & II \& III & III \& IV & IV \& V & VI & VI \& VII \\
\hline
\end{tabular}

The relationship of the new taxonomy to ABET educational program outcomes has also been determined. According to ABET, "engineering educational outcomes are specific statements that describe what students are expected to know and be able to do by the time of graduation. These relate to the skills, knowledge, and behaviors that students acquire in their matriculation through the program." Table 2 shows the relationship between ABET educational outcomes and the corresponding taxa of the proposed taxonomy.

Table 2. Comparison between ABET learning outcomes and the proposed taxonomy for STEM disciplines

\begin{tabular}{|c|c|}
\hline ABET Learning Outcomes & $\begin{array}{l}\text { Relevant proposed } \\
\text { Taxa, Figure } 8\end{array}$ \\
\hline 1. Apply knowledge of mathematics, science and engineering & II \& III \\
\hline 2. Design and conduct experiments, and analyze and interpret data & I \& III \\
\hline 3. Design a system, component, or process to meet desired needs & IV \& V \\
\hline 5. Identify, formulate, and solve engineering problems & III, IV \& V \\
\hline \multicolumn{2}{|l|}{ 7. An ability to communicate effectively } \\
\hline $\begin{array}{l}\text { 8. The broad education necessary to understand the impact of engineering solutions } \\
\text { in a global and societal context }\end{array}$ & VI \\
\hline \multicolumn{2}{|l|}{ 9. A recognition of the need for, and an ability to engage in life-long learning } \\
\hline \multicolumn{2}{|l|}{ 10. A knowledge of contemporary issues } \\
\hline $\begin{array}{l}\text { 11. An ability to use the techniques, skills, and modern engineering tools necessary } \\
\text { for engineering practice }\end{array}$ & VI \& VII \\
\hline
\end{tabular}

The computational simulation tools proposed in this work enhance educational outcomes for the students in majority of the elements of the Bloom's taxonomy as applicable to the STEM disciplines. For example, the experimentation, process design, data analysis and evaluation leads to the development of taxa \#I, \#II, \#III, \#IV, \#V and a part of \#VI in Figure 8. The skills and experiences obtained by the students also maps onto the ABET educational outcomes \#1, \#3, \#5, \#7, and \#8 as given in Table 2 above.

\subsection{Ability for Critical Thinking and Creativity}

The proposed methodology of computer experimentation allows students to change variables within permissible limits imposed by metallurgical phenomena or by process mechanics and equipment limitations. For example, the interpass time (the time between two consecutive deformation passes) depends on the speed of rolling and the input and the desired final thickness of material and can vary between $12 \mathrm{~s}$ to $2 \mathrm{~s}$. The temperature of deformation can be varied between 1373 to $1173 \mathrm{~K}$ depending on the process sequence designed for a chosen grade of steel. The students are thus able to explore important questions and problems in metal processing, 
conduct experiments, gather and assess relevant information, arrive at objective conclusions, test them against relevant theoretical models and practical industrial experience for model validation, and finally communicate the experiments, results and conclusions effectively with others in figuring out solutions to complex problems. These are all vital aspects of developing critical thinking skills in the students. The creativity is also enhanced by allowing new process sequence designs to work out the feasibility of the new approaches in metal processing and to generate metal products with novel combination of properties.

\section{Summary}

Process visualization using appropriate graphical user interfaces for industrially significant manufacturing processes such as ingot casting and hot rolling have been developed as educational tools. For ingot casting visualization the capacity and load in the production plan were plotted to evaluate adequacy of the designed plan as well as ramifications of the changes being considered. For hot rolling simulation and visualization mathematical models were collected and an expert system was built to capture process characteristics. The results of the computation were then used for visualization and experimentation. The computer based tools were used in the class room for teaching of these manufacturing processes. Analysis of the student assessment data of the applicable ABET derived learning outcomes, the correlation of these ABET learning outcomes to the modified Bloom's taxonomy cognitive outcomes for STEM disciplines shows that the students are benefited by the new educational tools as they develop an ability for critical thinking and creativity. It is thus concluded that the proposed computer-based experimentation and visualization tools enhances student's understanding of the complex processes and enriches their learning experience.

\section{References}

Bloom, B. S. (1956). Taxonomy of Educational Objectives. Boston, MA.

Girgis, M. (2010). ASEE Annual Conference.

Goldratt, E., \& Fox, J. (1984). The Goal: A Process of On-Going Improvement. North River Press, Inc.

Greene, A. (1996). Decision-Support Tools Provide Competitive Edge. Managing Automation, March, 8.

Manohar, P. A. (2008). The Development of Flexible Hot Rolling Technology Based on Through-Process Modeling, $137^{\text {th }}$ TMS Annual Meeting. In Frontiers in Process Modeling (pp. 9-13). Symposium, New Orleans.

Manohar, P. A. (2010). Thermomechanical Process Innovation and Optimization via Computer Modeling and $\begin{array}{lllll}\text { Simulation. } & \text { Materials } & \text { Science } & \text { Forum, } & 638,\end{array}$ http://dx.doi.org/10.4028/www.scientific.net/MSF.638-642.3883

Manohar, P. A., Lim, K., Rollett, A. D., \& Lee, Y. (2003). Computational Exploration of Microstructural Evolution in a Medium C-Mn Steel and Applications to Rod Mill". ISIJ International, 43, 1421-1430. http://dx.doi.org/10.2355/isijinternational.43.1421

Manohar, P. A., Shivathaya, S. S., \& Ferry, M. (1999). Design of an expert system for the optimization of steel compositions and process route. Expert Systems with Applications, 17, 129-134, http://dx.doi.org/10.1016/S0957-4174(99)00030-5

Mcllvaine, B. (1996). Planning and Scheduling Gets the Job Done. Managing Automation, August, 24-26.

Noderer, K., \& Henein, H. (1996). A survey on the use of expert systems in the iron and steel industry. Artificial Intelligence for Ironmaking and Steelmaking, 175-179.

Shivathaya, S. S. (1997). Material design in steelmaking utilizing mathematical modeling, knowledge-based and fuzzy logic approaches (Ph. D. Thesis, University of Wollongong, Australia).

Takahashi, K. (2008). Increase Profits with a Production Planning Scheduler. Retrieved September 2013, from http://www.lean-manufacturing-japan.com/advanced-planning-scheduling

Wu, P. Y. (1999). Visual Capacity Modeling for Interactive Production Planning. In Proceedings of the Computer Technology Solutions Conference (CTSC'99). Detroit, Michigan, American Society of Manufacturing Engineers.

Wu, P. Y. (2001). Visualizing Capacity and Load in Production Planning. In Proceedings of the Fifth International Conference on Information Visualization (pp. 357-360). London, England, IEEE Computer Society. http://dx.doi.org/10.1109/IV.2001.942082 


\section{Copyrights}

Copyright for this article is retained by the author(s) with first publication rights granted to the journal.

This is an open-access article distributed under the terms and conditions of the Creative Commons Attribution licence (http://creativecommons.org/licenses/by/3.0) 